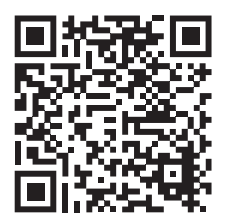

* Titular de la CAMEH.

* Subcomisionada médica de la CAMEH.

$\S$ Encargada de la Unidad

de Arbitraje de la CAMEH.

Comisión de Arbitraje

Médico del Estado

de Hidalgo (CAMEH),

Pachuca de Soto, Hidalgo.

Correspondencia: LRMF, lucianomendiola@ hidalgo.gob.mx; RTZ, rociotello@hidalgo.gob. mx;ACOA, anaolvera@ cameh.gob.mx Conflicto de intereses: Los autores declaran no tener conflicto de intereses en la elaboración de este artículo. Citar como: Mendiola FLR, Tello ZR, OlveraArellano AG. La COVID-19 como una oportunidad: la experiencia de la Comisión de Arbitraje Médico del Estado de Hidalgo. Rev CONAMED. 2021; 26(supl. 1): s22-s25. https://dx.doi. org/10.35366/102577

Financiamiento: La elaboración de este artículo no contó con financiamiento.

Recibido: 15/10/2021. Aceptado: 15/10/2021.

\section{La COVID-19 como una oportunidad: la experiencia de la Comisión de Arbitraje Médico del Estado de Hidalgo}

\author{
COVID-19 as an opportunity: the experience of the medical \\ arbitration commission of the state of Hidalgo \\ Luciano Ricardo Mendiola Figueroa, ${ }^{*}$ Rocío Tello Z, ${ }^{\ddagger}$ Ana Guadalupe Olvera-Arellano
}

\section{RESUMEN}

El artículo describe las estrategias empleadas por las autoridades de la Comisión de Arbitraje Médico del Estado de Hidalgo para afrontar la emergencia sanitaria declarada como consecuencia de la pandemia de COVID-19, sin poner en riesgo a los servidores públicos y, al mismo tiempo, sin afectar la calidad de los servicios que se ofrecen a los hidalguenses.

Palabras clave: Emergencia, Hidalgo, COVID-19, servicio, Comisión de Arbitraje Médico.

\section{ABSTRACT}

The article describes the strategies used by the authorities of the Medical Arbitration Commission of the State of Hidalgo to face the health emergency declared because of the COVID-19 pandemic, without putting public servers at risk and at the same time, without affecting the quality of the services offered to Hidalgo's population.

Keywords: Emergency, Hidalgo, COVID-19, service, Medical Arbitration Commission. 


\section{INTRODUCCIÓN}

La mente humana en su área de comodidad traiciona y cree que todo sigue y será igual, que lo cotidiano es lo de siempre y que todo lo tiene bajo control. Y la pandemia llegó del otro lado del planeta, desde un lugar tan lejano como desconocido para México y como sombra silenciosa, invisible y traicionera fue permeando, ganando terreno, invadiendo cuerpos, saturando hospitales y cementerios, cerrando escuelas, empresas, instituciones y dejando las calles vacías.

Así, como afirma Pérez, debemos aprender las lecciones del dolor que ha dejado en toda la humanidad esta enfermedad y trabajaremos sobre aquello que dignifique al ser humano, pongamos la mirada en lo esencial y ampliemos el horizonte hacia el reconocimiento del valor y la cualidad de todo ser vivo que habita en este planeta; sólo la apertura de una nueva perspectiva hacia la expansión de nuestra conciencia nos permitirá potenciar valoresy recursos olvidados del ser humano que tienen que ver con la compasión, solidaridad y empatía, en un nuevo contexto de hermandad donde puedan compartir todos.

La COVID-19 nos ha hecho vivir tiempos difíciles interrumpiendo nuestra vida cotidiana debido a la amenaza de socavar la salud de los seres humanos y nos ha hecho sentir vulnerables, ya que hemos visto a nuestros compañeros de trabajo enfermarse y algunos desafortunadamente han fallecido, llenando el ambiente de un pavoroso silencio, miedo y luto.

Después de todo, como Giacchino² afirma:

La pandemia nos debería hacer reflexionar del hecho de que tanto individual como colectivamente necesitamos de una catástrofe para pensar en aplicar el sentido común, para preguntarnos qué estamos haciendo de nuestras vidas y para focalizar en lo importante.

¿La pandemia de COVID-19 generará cambios en el orden mundial? ¿Lo hará en la vida cotidiana de muchos de nosotros, en la educación, el trabajo, la atención médica o las relaciones sociales? ¿Traerá cambios?, de eso no hay duda. La pregunta ahora gira en torno a si serán los que la humanidad necesita para bien.

Esta crisis ha creado un escenario inédito en nuestro país como en casi todo el mundo, tanto desde el punto de vista social como sanitario, lo que ha desencadenado múltiples dilemas e incertidumbre en distintos niveles: la sociedad en su conjunto, los sistemas de salud, en los médicos y profesionales de la materia.

\section{DESARROLLO}

A pesar de todo, la vida continúa y hay que seguir adelante con la toma de decisiones, acompañar, servir y resolver. Al tomar posesión como titular de la Comisión de Arbitraje Médico del Estado de Hidalgo (CAMEH) en julio de 2020, ya habían transcurrido cuatro meses del inicio de la pandemia y la comisión trabajaba por guardias en un horario reducido. Desde hace un año, se tomó la decisión de ir incorporando al personal progresivamente y desde febrero se viene trabajando con todo el personal, del cual se registra sólo un enfermo por COVID-19. Así, se han obtenido los siguientes resultados dados a conocer oportunamente a través del Informe Anual de Actividades 2020 y el de actividades de enero a agosto de 2021.3,4

Por parte de la Subcomisión Médica es importante señalar que uno de los factores que deterioran la calidad de vida del ser humano es el sentirse no atendido de forma adecuada cuando su salud está afectada. En esta área el personal está capacitado y sensibilizado para ofrecer una atención oportuna y resolutiva, logrando de esta forma la satisfacción de las partes comprometidas en los diferentes trámites que se realizan. Durante este periodo se anexan los servicios realizados de forma presencial, por correspondencia, por vía electrónica y telefónica y que consisten en asesorías, orientaciones, gestiones inmediatas y quejas.

En la Unidad de Conciliación, por la suspensión de plazos y términos, se continuó con la actualización de archivos informáticos y al reanudarse de inmediato se ha dado cauce de los casos pendientes y en la actualidad se ha logrado concluir nueve quejas.

Para dar a conocer de forma permanente las funciones de la comisión y la manera en que este organismo puede ayudar en los conflictos por prestación de servicios de salud, aprovechamos el desafío y a través de la tecnología nos enlazamos con universidades, instituciones de salud públicas y privadas, impactando hasta el 31 de agosto de 2021 
a 4,400 personas con conferencias que tratan los temas: ¿Qué es la Comisión de Arbitraje Médico?, Bioética, Expediente Clínico y Relación MédicoPaciente.

Hemos establecido contacto con servidores públicos del Gobierno del Estado, con todas las presidencias municipales y público en general para dar a conocer los servicios que otorgamos y las funciones que llevamos a cabo a través de conferencias, entrevistas en radio y televisión, prensa escrita, programas en medios digitales como Facebook Live y la producción de un video informativo de la CAMEH.

Se participa con la Dirección de Profesionalización para anexar en los buzones de comentarios que se ubican en los hospitales y centros de salud, los datos de contacto para la atención de quien lo solicite y hemos contactado con las áreas de calidad de diversos hospitales de los servicios de salud de Hidalgo para llevar a cabo encuestas de satisfacción en la atención, cuyos resultados nos permitan hacer recomendaciones para mejorar la calidad en la prestación de servicios de salud.

Como una estrategia de comunicación se participó en las Jornadas de Intervención Sanitaria organizadas por la Secretaría de Salud de Hidalgo para mitigar efectos de la pandemia en varios municipios, en donde la CAMEH se dio a la tarea de distribuir pósteres y trípticos relacionados con diferentes temas de los derechos de los pacientes y del personal de salud, así como dar a conocer las acciones de apoyo de la Comisión a pacientes y familiares de enfermos COVID-19.

Se continúa atendiendo a los usuarios de forma ininterrumpida presencialmente y/o a través de la vía telefónica e Internet y se ha instruido a quienes tienen primer contacto, que den todas las facilidades y prioridad a las inconformidades relacionadas con la COVID-19.

Por lo que corresponde a la Subcomisión Jurídica no se han presentado asuntos para desahogar en la etapa decisoria del proceso arbitral; sin embargo, se ha pedido el apoyo jurídico a quien funge como encargada de la Unidad de Arbitraje para atender las instrucciones del Secretario de Salud en temas sobre la Comisión de Bioética del Estado de Hidalgo y la Coordinación Especializada en materia de voluntad anticipada, que se brinda en auxilio al Titular de la Dirección de Relaciones
Intersectoriales de la Secretaría y ex Subcomisionado Jurídico, Mtro. Alejandro Pacheco Gómez.

Para dar seguimiento a la instrucción en cuanto al tema de bioética, se ha mantenido una estrecha colaboración con la Comisión Nacional de Bioética y con las unidades médicas de Servicios de Salud de Hidalgo y del Instituto Mexicano del Seguro Social, especialmente en actividades de difusión sobre la importancia de la bioética en la prestación de servicios de atención médica.

Igualmente se han llevado a cabo trámites ante la Comisión de Mejora Regulatoria y el Registro Único de Trámites y Servicios, lo que nos permite ofrecer mejores y eficientes servicios a la población hidalguense. Por ello, se recibió una capacitación para realizar los mismos ante la primera, ya que de forma periódica se emitieron acuerdos para suspender plazos y términos de los procedimientos administrativos en la Comisión de Arbitraje Médico, como una medida sanitaria para evitar y disminuir los contagios por el virus SARS-CoV-2.

Con relación a las capacitaciones recibidas por personal adscrito a la subcomisión, fueron sobre temas vinculados a los aspectos bioéticos, deontológicos y jurídicos de la prestación de servicios médicos durante la pandemia.

Es importante resaltar que en noviembre de 2020 se llevó a cabo el Seminario Anual de la CAMEH denominado «Deontología médica en tiempos de pandemia» teniendo un registro de más de 900 personas con una audiencia de aproximadamente 400 personas a través de las cuentas institucionales de la Comisión en Facebook y YouTube, organizado por el subcomisionado jurídico, la encargada de la unidad de arbitraje y el titular de la unidad de informática.

El personal de la subcomisión descrito también brindó asesoría en materia de protección de datos personales y para la elaboración de cartas de consentimiento informado, temas que son parte inherente a los derechos de los usuarios y, por consiguiente, de las obligaciones del prestador de servicios médicos, por lo que es imperante la actuación de la Subcomisión a la luz de los principios jurídicos.

En la Unidad de Gestión Pericial se elaboraron 30 dictámenes periciales solicitados por diversas autoridades, sin que a la fecha se trate de algún asunto específico de atención médica 
derivada de la enfermedad COVID-19, ya que la materia de las peticiones es determinada por quien requiere la intervención de la Comisión de Arbitraje Médico.

\section{CONCLUSIONES}

Para finalizar, quisiera citar a la Madre Teresa de Calcuta quien respondió cuando le preguntaron cuál era para ella la peor enfermedad y dijo: La gran enfermedad hoy en día no es la lepra o la tuberculosis, es el sentimiento de no ser querido. Sin duda esta frase es tan real y auténtica como en 1979 al recibir el premio Nobel. Hemos escuchado de enfermos de COVID que mueren solos, sin poder ser despedidos por sus familiares y amigos. Pero también de gente que han perdido empleos, que se han quedado sin sus negocios o que han muerto de depresión debido a la tristeza y la soledad originada por el famoso Quédate en Casa.

Definitivamente esta pandemia por COVID-19 ha sido una gran escuela para enfrentar el siglo XXI. Hemos tenido que aprender a trabajar en línea y a utilizar las nuevas plataformas que muchos no solíamos ocupar, tales como Zoom o Meet. En esta lección que un virus vino a darnos, tuvimos que hacer amigos, ser jefe y empleados en la comodidad de nuestro domicilio y al mismo tiempo solucionar problemas y dar respuestas a pesar de los ladridos de los perros, las conversaciones entre maestras y alumnosy todos aquellos ruidos que pueden sonar en un día común y corriente en el hogar.

Indudablemente, la pandemia está trayendo cambios importantes, incluyendo los aprendizajes y las cosas positivas, porque, aunque nos parezca difícil de creer, hemos tenido experiencias buenas. En el caso de la CAMEH, los compañeros de trabajo están mucho más receptivos y dispuestos a ayudar. El personal que otorga servicio al usuario se ha sensibilizado, ya que, dadas las circunstancias, hoy en día todos hemos tenido un familiar, un amigo, un conocido en el hospital y sabemos de la importancia de ser bien atendidos, de recibir informes claros y verdaderos y sobre todo de la empatía que debe haber en la relación médico-paciente.

Si bien es cierto que el objetivo de creación de la Comisión es encomiable y su labor valiosa, en tanto su papel de conciliador entre la sociedad y los profesionales de la salud en el contexto de la emergencia, su importancia se ha multiplicado.

Así, debemos continuar con el trabajo realizado hasta ahora, haciendo pausas para realizar introspecciones que nos permitan reconducir el camino, con el ánimo de ofrecer el mejor de los servicios a los hidalguenses.

En la CAMEH buscamos fomentar la prevención, el sentido común, la solidaridad entre compañeros. Las buenas acciones comienzan en casa: si hay colaboración, apoyo y buen humor al interior, lo habrá para los usuarios. Buscamos siempre hacer todo en equipo: revisar buzones, contestar correos, analizar asuntos, para garantizar imparcialidad y buenos resultados.

\section{REFERENCIAS}

1. Pérez CC. Reflexiones sobre la pandemia COVID 19. Revista de Investigación Psicológica. (Especial). 2020.9-14. [Recuperado en 23 de septiembre de 2021] Disponible en: http://www.scielo.org.bo/scielo.php?script=sci_ arttext\&pid=S2223-30322020000300003\&lng=es\&tlng=es

2. Giacchino A. Reflexiones en tiempos de la pandemia de COVID-19. Fundación de Historia Natural Félix de Azara; Universidad Maimónides. 2020. Recuperado a partir de: https://www.maimonides.edu/descargas/Reflexiones-entiempos-de-pandemia-2020-7.pdf

3. Comisión de Arbitraje Médico del Estado de Hidalgo. Informe anual de actividades 2020. 2021. [Conjunto de datos].

4. Comisión de Arbitraje Médico del Estado de Hidalgo. Informe de actividades enero a agosto 2021. 2021. [Conjunto de datos]. 